\title{
Seroepidemiological Studies of Cutaneous Leishmaniasis in the Campeche State of Mexico
}

\author{
Amalia Monroy-Ostria/ ${ }^{+}$, Tayde Sosa-Cabrera*, Beatriz Rivas-Sanchez, \\ Rosaura Ruiz-Tuyu*, Ana R Mendoza-Gonzalez**, Luis Favila-Castillo
}

\author{
Departamento de Inmunologia, Escuela Nacional de Ciencias Biologicas del IPN, Carpio y Plan de Ayala, \\ Colonia Santo Tomás, 11340 México city, México *Centro de Investigactones Biomédicas, Universidad \\ Autonoma de Campeche **Servicios Coordinados de Salud de Campeche, SSA Mexico
}

Seroepidemiological studies of cutaneous leishmaniasis were carried out in 169 individuals in a rural area of the Campeche state of México. Fifty showed cutaneous lesions suggestive of leishmaniasis, $70 \%$ were parasite positive and $96 \%$ skin test positive. An overall $40 \%$ positivity to skin test with Montenegro 's antigen was found. Most of the affected individuals were males from 11 to 30 years-old. Antibodies were determined by immunojluorescent antibody test (IFA) and by Western blot. Two antigen preparations were used, one from a Leishmania mexicana strain which produced localized cutaneous leishmaniasis (LCL) and the other from a diffuse cutaneous leishmaniasis (DCL). In the general population from the area of study $19 \%$ gave positive IFA tests with DCL antigen and $20 \%$ with LCL antigen while for the patients $67 \%$ gave positive IFA tests with DCL and $71 \%$ with LCL. By Western blot analysis most of the patients recognized more antigens in the DCL than in the LCL strain. In the DCL strain $78 \%$ ofpatients recognized a $105 \mathrm{kDa}, 34 \%$ a $139 \mathrm{kDa}, 28 \%$ a $117 \mathrm{kDa}$ and $26 \%$ a $205 \mathrm{kDa} \mathrm{MW}$ antigen. In the LCL strain 40\% ofpatients recognized a $205 \mathrm{kDa}$ and $22 \%$ a $175 \mathrm{kDa}$ antigens.

Key words: seroepidemiology - cutaneous leishmaniasis - Campeche state - Mexico - Western blot

American cutaneous leishmaniasis is caused by species belonging to two complexes: Leishmania mexicana and $L$. braziliensis. Species of $L$. mexicana produce either self-healing ulcerative cutaneous lesions (localized cutaneous leishmaniasis: LCL) with early positive skin test and low titers of serum antibodies or nodular diffuse cutaneous lesions (diffuse cutaneous leishmaniasis: DCL) with very heavy loads of parasites in macrophages, with negative skin test, higher serum antibodies titers and which do not respond to treatment.

In Mexico, cutaneous leishmaniasis (CL) was recorded for the first time in Campeche state by Seidelin (19 12) who called it "Chicleros Ulcer" because it was frequently found in chicle workers. Nowadays CL is becoming important because of the number of cases appearing per year, some of such cases being DCL. CL in Mexico has been found mainly in the forests of Campeche, Quintana Roo, Tabasco, Chiapas, Oaxaca and Veracruz

\footnotetext{
This work was supported by a grant from the Direccion de Estudios de Posgrado e Investigación, IPN, Mexico and from D.G.I.C.S.A:863091. A Monroy-Ostria and L Favila-Castillo are fellows from COFAA, IPN, Mexico. ${ }^{+}$Corresponding author. Fax: +52-5-396.3503

Received 13 September 1995

Accepted 9 September 1996
}

states, it has also been found in semi-arid regions of the country (Velasco et al. 1989). Nevertheless, incidence and prevalence rates in those places are unknown because CL became a notifiable disease in Mexico only at the end of 1986 and proper epidemiological studies have not been carried out on CL in other states apart from Campeche. "Chicleros ulcer" was recorded in Campeche state by several authors at different times, Seidelin (1912), Beltrán and Bustamante (1942), Biagi (1953a) and Andrade-Narvaez et al. (1990).

The most reliable methods to confirm the diagnosis of leishmaniasis are the identification of the parasite in thin smears made from superficial scrapings of the ulcers and isolation of the parasite by inoculation of culture media or susceptible animals (Navin et al. 1990), but CL parasitological diagnosis is difficult in a patient with more than one year of evolution and furthermore in the field and small towns or rural areas there are no facilities to grow the parasite in culture or in animals. For these reasons it is necessary to find methods for an accurate diagnosis of CL but specially those which can be used in small laboratories in the endemic areas.

It has been shown by Andrade-Narvaez et al. (1990) and Souza et al. (1992), that the Montenegro skin test (MST) is very useful to identify or characterize areas in which there is a risk of $\mathrm{CL}$ infec- 
tion. MST has a very good sensitivity, but patients who have been cured remain giving positive skin reactions. Serological techniques together with the skin test could be useful to identify accurately patients with CL (Garcia-Miss et al. 1990, Guimarães et al. 1990).

The aim of this work was to determine the reactivity to MST of individuals living in the endemic district of Holpechen, Campeche as well as to measure by indirect immunofluorescent antibody test (IFA) their specific antibodies to antigens of two strains of L.mexicana isolated in Mexico. We also searched by Western blot analysis which antigens of this parasite are recognized by patients with LCL of the same area to try to find a more dependable method of diagnosis of CL.

\section{MATERIALS AND METHODS}

Study population - The state of Campeche has an area of $56,850 \mathrm{~km}^{2}$. Tropical humid, high forests predominate, covering about $60 \%$ of the state. Campeche state has a population of 533,703, around $45 \%$ of which work in the forest (Andrade-Narvaez et al. 1990). People from rural areas (169 persons) of the Holpechen district accepted to participate in the study (101 males and 68 females). The following data was obtained from all participants: age, sex, occupation and places where they had lived or traveled. MST was performed on the individuals and sera were obtained for serological analysis.

In the first part of the study individuals with ulcerative skin lesions were considered as suggestive cases of leishmaniasis. Parasitological diagnosis of cutaneous leishmaniasis was attempted in individuals with suggestive lesions by inoculation of aspirate into biphasic Senekji's and RPMI media and microscopic search of amastigotes in Giemsa stained thin smears made from superficial scrapings of the ulcers. All patients were treated with intralesional administration of glucantime. A confirmed case of cutaneous leishmaniasis was considered if a positive Leishmania culture was observed or if the parasite was found in the thin smears. The other patients were considered leishmaniasic because, although the parasite could not be demonstrated, they were MST positive and responded to the treatment. Two patients in whom Leishmania could not be found, were MST negative and did not respond to the treatment were later diagnosed as skin cancer by histopathological studies. The lesion evolution time in the patients was from 4 months to 8 years.

Strains of Leishmania - Two L. mexicana strains, a L. m. mexicana MHOM/MX/88/HRC JS isolated from a patient with LCL and one $L . m$. mexicana $\mathrm{MHOM} / \mathrm{MX} / 84 / \mathrm{ISET}$ GS from a patient with DCL were used to prepare antigens. Both patients came from the Tabasco state of Mexico, very close to Campeche.

Sera - Two hundred and eighteen sera were analyzed for specific antibodies. 119 sera were obtained from individuals living in the endemic area of Holpechen district (healthy individuals from endemic area). 48 were from patients with leishmaniasis (described above); 31 were from patients from Mexican states other than Campeche and with diagnosis of Chagas' disease and 20 came from healthy people that have lived in Mexico city (nonendemic area), who have never been in endemic areas, were MST negative and had no lesions suggestive of cutaneous leishmaniasis (healthy individuals from non-endemic area).

Preparation of antigens - Leishmania parasites were grown in RPMI 1640 medium (Sigma Chem. St Louis, Mo, USA) supplemented with $10 \%$ fetal calf serum. Leishmanin was prepared with promastigotes of 9-10 days of culture which were harvested by centrifugation (at $1500 \mathrm{~g}$ for $5 \mathrm{~min}$ at $4^{\circ} \mathrm{C}$ ) and washed three times in phosphate buffered saline (PBS) $\mathrm{pH}$ 7.4. The pellet was resuspended in $0.05 \%$ phenol $0.85 \% \mathrm{NaCl}$ at a final concentration of $5 \times 10^{6}$ parasites $/ \mathrm{ml}$ for skin test (Bray 1980), or in an antiproteolytic electrophoresis sample buffer containing $0.04 \mathrm{M} \mathrm{NaCl}, 10 \mathrm{mM}$ PMSF, 10mM TLCK and Tris $\mathrm{pH} 8.0$ for Western blot analysis.

Skin test - $0.1 \mathrm{ml}$ of Montenegro's antigen (leishmanin) were injected intradermally in the volar surface of the forearm. The reaction was observed at 24, 48 and $72 \mathrm{hr}$. A positive reaction was considered when an induration of $5 \mathrm{~mm}$ or more was observed.

Antibody test - The IFA test was used to measure anti L. mexicana antibodies (IgG). Promastigotes of 9-10 days of culture in RPMI medium were used as antigen. They were washed twice with PBS, $8 \times 10^{4}$ promastigotes were spread as a thin "dot smear" on slides and allowed to dry thoroughly and fixed with absolute methanol. The assay was performed as described by Bray (1980), using as a starting point a 1:4 serum dilution. Fluorescent labeled goat anti human IgG (Cappel laboratories, USA), was used to develop the reaction.

Antigen recognition by Western blot - Antibodies against different antigens of Leishmania were determined by Western blot analysis as described by Towbin et al. (1979) with some modifications: promastigotes of both LCL and DCL strains of Leishmania were used for the analysis. Electrophoresis in $10 \%$ SDS-PAGE $10 \mathrm{~cm}$ gels was carried out with $3 \times 10^{8}$ promastigotes from one or the other strain of L. mexicana. The gels were run for $40 \mathrm{~min}$ at $30 \mathrm{~mA}$ and electrophoretically transferred to nitrocellulose membranes (Amersham, $0.45 \mathrm{pm}$ pore-size) overnight at $100 \mathrm{~mA}$. After blocking overnight with bovine serum albumin (Sigma 
Chem., USA) the membranes were incubated with patient's sera, diluted $1: 20$, sera from healthy individuals living in endemic areas or healthy individuals from non-endemic areas. To develop the reaction peroxidase-labeled goat antihuman IgG (Cappel laboratories, USA) was used.

\section{RESULTS}

Parasitological studies - Lesions suggestive of CL were found in 50 of the 169 individuals examined from the endemic area. $86 \%$ of them were male and $14 \%$ female and the most affected age was 11 to 30 years of age (Table I). Lesions ocurred mainly on the ear (39\%) followed by the forearm $(18 \%)$ and on the face $(11 \%)$. In $70 \%$ of the patients the parasite was either isolated or observed by direct microscopy.

Skin test - Skin test was applied to a total of 191 individuals, 169 from endemic area and 22

\section{TABLE I}

Age and sex distribution of patients with lesions suggestive of cutaneous leishmaniasis

\begin{tabular}{ccc}
\hline \multirow{2}{*}{$\begin{array}{c}\text { Age } \\
\text { (years) }\end{array}$} & \multicolumn{2}{c}{ Sex } \\
\cline { 2 - 3 } & Male (\%) & Female (\%) \\
\hline $0-10$ & $2(4)$ & $1(2)$ \\
$11-20$ & $9(18)$ & $1(2)$ \\
$21-30$ & $16(32)$ & $1(2)$ \\
$31-40$ & $6(12)$ & $2(4)$ \\
$41-50$ & $5(10)$ & $1(2)$ \\
$51-60$ & $3(6)$ & $1(2)$ \\
$61-70$ & $2(4)$ & 0 \\
\hline Total & $43(86)$ & $7(14)$ \\
\hline
\end{tabular}

from non-endemic area. The strongest reaction was observed at $48 \mathrm{hr}$ with around $1 \mathrm{~cm}$ reactions being common. $16 \%$ of healthy people, and $96 \%$ of patients from the endemic area gave positive skin tests. This gives a $40 \%$ overall positivity in this endemic area. Healthy individuals with no lesions from non-endemic areas gave negative skin tests. Two patients from the endemic area showing lesions similar to cutaneous leishmaniasis and who were later diagnosed as skin cancer (see materials and methods), were also skin tested and gave a negative result (Table II).

Serum antibodies by IFA - When the LCL strain of L. mexicana was used as antigen, all the 20 sera from donors living in non-endemic areas (Mexico city) gave negative results while only 3 from patients with leishmaniasis gave negative results. The other 45 from patients with leishmaniasis gave positive tests between 1: 16 and 1: 1024 dilutions. Most of the individuals from the endemic area gave negative tests (112) and 7 were positive between
TABLE II

Montenegro skin test positivity for the different groups tested

\begin{tabular}{lcc}
\hline Group & $\begin{array}{c}\text { No. of } \\
\text { subjects }\end{array}$ & $\begin{array}{c}\text { No. } \\
\text { positive (\%) }\end{array}$ \\
\hline Healthy individuals from EA & 119 & $19(16)$ \\
Patients with skin lesions & 50 & $48(96)$ \\
Total from EA & 169 & $67(40)$ \\
Healthy individuals from NEA & 22 & $0(0)$ \\
\hline
\end{tabular}

EA: endemic area

NEA: non endemic area

1:4 and 1:32 dilutions. Only two patients with Chagas' disease diagnosis gave a positive test, both at 1:32 dilution while the rest (29) were negative (Fig. 1). One of the patients diagnosed as skin cancer gave a negative test and the other gave a 1: 16 titer. Neither of them were included in Fig. 1. Table III shows the positivity results of the different groups using as cut-off point a 1:32 dilution which gives a $100 \%$ specificity for the assay. It is clear that the results using two different strains of Leishmania (DCL and LCL) are very similar, although LCL gave a positive result with two more patients. The patients with leishmaniasis gave around $70 \%$ positivity which gives an overall positivity of $20 \%$ for the population from the endemic area (Table III). When the antibody titers obtained with one or the other Leishmania strain are compared, there seems to be a tendency to obtain higher titers with LCL (Fig. 2).

Western blot analysis - All the 48 sera from patients with leishmaniasis plus 19 from healthy

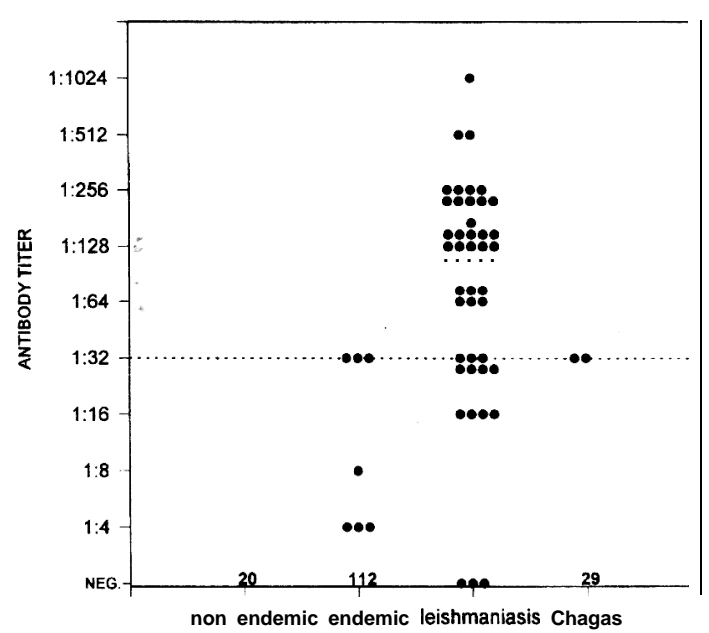

Fig. 1: antibody titer distribution of the different groups of sera tested using localized cutaneous leishmaniasis antigen. The numbers at the bottom of the columns indicate the number of negative sera for each group at 1:4 dilution. 


\section{TABLE III}

Immunofluorescence test results of the different groups of sera tested

\section{Groups}

No. of No. positive

Iealky individuals from $\mathrm{EA}$ i19 0 o Patients with leishmaniasis $48 \quad 32(67) \quad 34(71)$ Total from $E_{A} A \quad 169 \quad 32(19) \quad 34(20)$ Healthy individuals from NEA 20 o 0 Pattients witl Chagas' disease 31 0 o

EA: endemic area; NEA: non endemic aren; DCL: diffuse cutaneous leishmaniasis; LCL: localized cutaneous leishmaniasis

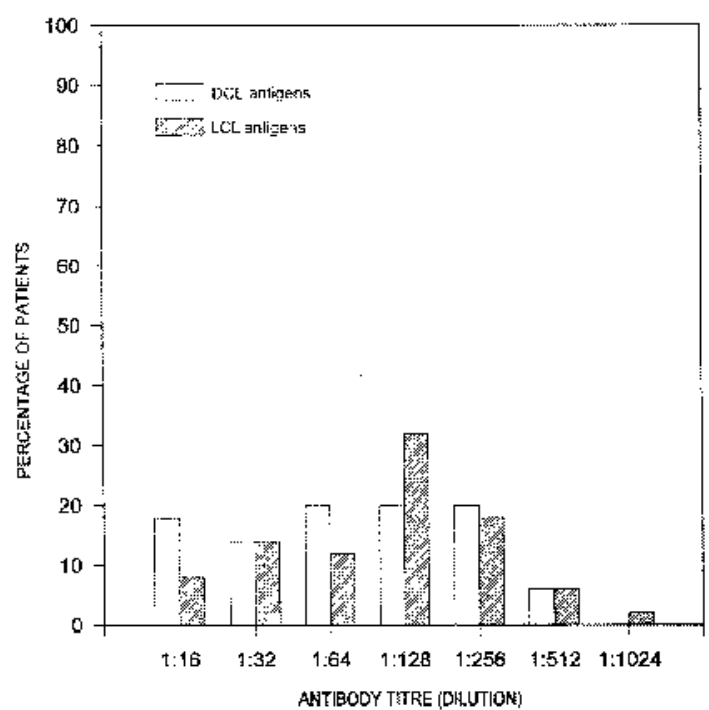

Fig. 2: antibody titer distribution, expressed as percentage of the total of patients with leishmaniasis (48) when assayed with two different Lesshmania strains. Open bars are resulls with diffuse cutaneons leishmaniasis (DCL) and hatched bars results with localized eutancous leishmaniasis (LCL).

individuals from endemic area and 10 from non endemic area were analyzed. Patients with leishmaniasis recognized two more antigens in the $\mathrm{DCL}$ strain than in the LCL strain. In the DCL strain, among other antigens, $78 \%$ of paticnts recognized a $105 \mathrm{kDa}$ molecular weight antigen, $34 \%$ a 139 $\mathrm{kDa}, 28 \%$ a $117 \mathrm{kDa}, 26 \%$ a 205 and $88 \mathrm{kDa}$ antigens. In the LCL strain three antigens were most recognized, $205 \mathrm{kDa}$ ( $40 \%$ of the patients), 175 $\mathrm{kDa}(22 \%)$ and $159 \mathrm{kDa}(20 \%)$.

Less than $12 \%$ of the patients recognized antigens below $83 \mathrm{Kda}$ in both strains of Leishmania (Fig. 3). Antigens of $70,98,126$ and $148 \mathrm{kDa}$ were recognized by some sera from healthy individuals from endemic and non endemic arcas (data not shown) and also by some patients so these anti- gens are excluded from the analysis of reactivity shown in Fig. 3.

\section{DISCLSSION}

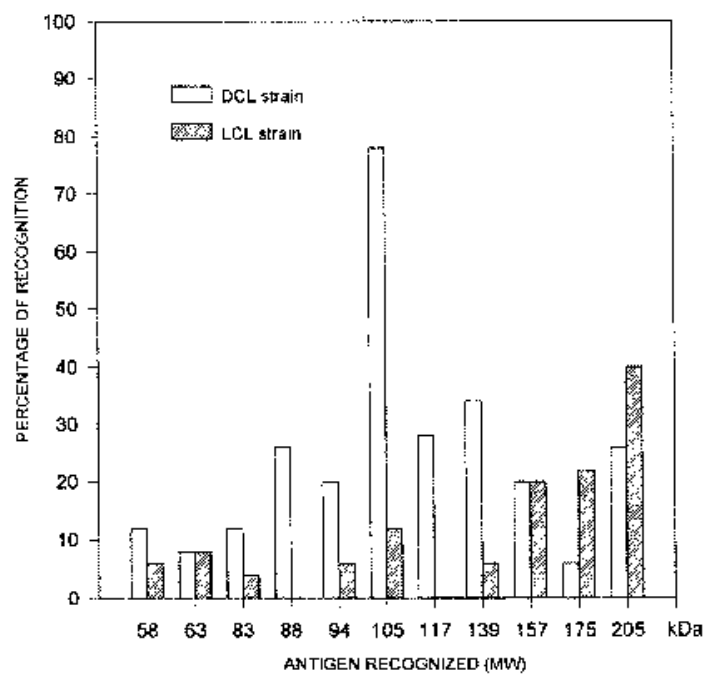

Fig. 3: percentage of recognition of different Letishomis antigens by Western blot by sera of 48 patients with leishmuniasis. Opon bars are results with difluse cutaneous leishmaniasis (DCL) and hatched bars resulis with localized cutaneous leishmaniasis (LCL).

In the present study carried out in the Holpechén district of Campeche state a $40 \%$ overall positivity to MST was found (Table II). In patients with suggestive lesions MST became positive in early stagcs of the infection as patients with a month of evolution gave skin reactions greater than $5 \mathrm{~mm}$; there was no relationship between the time of evolution and the size of the skin test (data not shown). These results confirm those of Biagi (1953b), who found 36 out of 84 (43\%) field workers with positive MST reactions in Escárcega district of Campeche. Andrade-Narváez et al. (1985) who found 66 out of $330(20 \%)$ members of the Mexican army-with positive MST in the Peninsula of Yucatán (near Campeche) and Andrade-Narvacz et al. (1990), who found in several rural areas of Campeche state a $43 \%$ MST positivity. It seems that the incidence of CL has been maintained at the same level at different times in different endemic areas of Campeche.

As Biagi (1953a) and Andrade-Narvaéz et al. (1990) reported, we found also a cortelation among age, sex, occupation and positive skin lesions. Table I shows that the range of age more affected was from 11 to 30 years and that the most affected group was $21-30$ year-olds. $86 \%$ of the 50 patients werc male and $14 \%$ female (compared to $60 \%$ males and $40 \%$ females in the population studied from the endemic area), and agriculture was their 
main occupation. It seems that the risk of infection is due to the agricultural occupation, because the women and the 3 children under 10 years $(2$ males and 1 female) who were infected (Table I), regularly went to work in the field. There appears to be no urban transmission of leishmaniasis in the area studied.

In serological studies Garcia-Miss et al. (1990) found $76 \%$ of patients with "Chicleros Ulcer" with positive antibodies by ELISA in some rural areas different from Holpechen and report that their assay has a $76 \%$ sensitivity and $100 \%$ specificity. In the present study (Fig. 1, Table III), $71 \%$ of positivity by IFA test was found in our patients with leishmaniasis which results in $20 \%$ positivity for the general population of Holpechen using a cut off point of 1:32. Using the healthy population from the endemic area to evaluate the performance of our assay, we have a $70.8 \%$ sensitivity and $100 \%$ specificity.

We were also interested in finding out if the strain of Leishmania used for antibody determinations influences the results. Fig. 2 shows the titers obtained in the same patients using both strains of Leishmania (LCL and DCL) and we can see that there is not much difference between the reactivity against both strains of Leishmania, although with the LCL strain the IFA titers were slightly higher, resulting in only 4\% more positives among leishmaniasis cases (Table III).

Our results show that antibody determination alone is not of much help for the diagnosis of leishmaniasis as around $30 \%$ of the patients gave titers similar to those of healthy people in the endemic area and three patients were even negative (Fig. 1). A combination of antibody determination and skin test seems to be more valuable as an aid for the diagnosis of leishmaniasis in this endemic area. As mentioned above, two patients who had skin lesions were MST negative and were later diagnosed as having skin cancer. One of these patients was negative by IFA and the other had a titer of 1:16 (data not shown).

Excluding these two patients, who obviously are not leishmaniasic, the performance of the MST in this endemic area is a $100 \%$ sensitivity and $84 \%$ specificity with a $100 \%$ negative predictive value. The usefulnes of such a high negative predictive value is illustrated by the two cases of skin cancer unexpectedly found in our studied population and who were MST negative.

On the other hand, if the cut-off point for the IFA assay is set to 1: 16, the sensitivity is increased importantly to $85.4 \%$ while the specificity is lowered only slightly (to $97.4 \%$ ).

We can conclude that for the endemic area studied, the presence of an ulcerative skin lesion, an antibody titer by IFA above 1:16 and a positive Montenegro skin test can be considered as a positive diagnosis of leishmaniasis even if the parasite cannot be isolated or demonstrated.

Our results and those of Garcia-Miss et al. (1990) clearly indicate that the serological assays for leishmaniasis must be improved, specially in their sensitivity. As a first step toward this goal, we analyzed the reactivity of our serum samples by Western blot. As Fig. 3 shows, there was an important difference in antigen recognition of the sera of the patients with CL between both strains of $L$. mexicana. In spite of the fact that the LCL strain was slightly better for detection of Leishmania antibodies than DCL by the IFA test, by Westem blot the patients recognized more antigens in DCL and some of them with higher frequency than in LCL. Another important feature is that in both strains of Leishmania few patients recognized antigens in a range of 40-70 $\mathrm{kDa}$ where GP63, one of the important antigens of Leishmania, is found (Moody 1993). This antigen has been considered as a candidate for a Leishmania vaccine. On the other hand $78 \%$ of patients recognized a $105 \mathrm{kDa}$ antigen in the DCL strain. In this range of Mw the secreted acid phosphatase (SAP) would be found; this enzyme is thought to contribute to parasite survival in the host, as it is involved in pathogenicity and parasite nutrition (Hassan \& Coombs 1987, Ilg et al. 1991). In the LCL strain $40 \%$ of the patients recognized a $205 \mathrm{kDa}$ antigen, but we do not know the significance of this, because there is no information on important antigens of this molecular weight in L. mexicana.

The Western blot analysis indicates that it might be possible to develop better serological assays for epidemiology and diagnosis. The $105 \mathrm{kDa}$ antigen was recognized by almost $80 \%$ of patients and by none of the 19 sera from healthy persons from endemic area which included some sera with IFA titers of $1: 32$ and below. Other antigens were also recognized-by $20-30 \%$ of the patients (Fig. 3) so we think that it would be possible to find specific antigens of. Leishmania which could be used to improve the serological assays for the diagnosis and seroepidemiology of leishmaniasis.

\section{ACKNOWLEDGMENTS}

To Dr Fernando Arjona from Servicios Coordinados de Salud Pública, Secretaria de Salud de Campeche. To Dr Victor Monteón from Instituto Nacional de Cardiologia for providing Chagas' disease sera.

\section{REFERENCES}

Andrade-Narvaez F, Valerio-Castro E, Simmonds-Diaz E, Cruz-Ruiz AL, Garcia-Miss MR, Canto-Lara SB 1985. Mexican cutaneous leishmaniasis. Allergic index in Army Forces. Revista Sanidad Militar 
26 Cutaneous teishmaniasis in México - A Monroy-Ostria et al.

(Méve) 39: 152-154.

Andrade-Narvacz. FJ, Simmonds-Díaz E, Rico-Aguilar $\mathrm{S}$, Andrade-Narvácz M, Palomo-Cetina A, CantoLara SB. Carcia-Miss MR, Madera-Sevilla M, Albcrtos-Alpuche $\mathrm{N}$ 1990. Incidence of localized cutancous leishmaniasis (Chiclere's ulcer) in Mexico. Trans R Soc Trop Med Hyg 84: 219-220.

Beltrán E, Bustamante F 1942. Datos epidemiologicos acerca de la "ulcera de los chicleros" (leishmaniasis americana) en Mexico. Rev Inst Salubridad v Enfermedades Tropicales (México) 3: 1-28.

Biagi Fi 1953a. Sintesis de 70 historias clinicas de leishmaniasis tegumentaria en Mexico (úlcera de los chicleros). Medicina (Mexico) 33: 385-396.

Biagi F 1953b. Intrademoreacciones con leishmanina en Fiscárcega. Medicina (México) 33: 225-260.

Bray RS 1980. Leishmaniasis, p. 65-75. In V Houba, Immunological Investigation of Tropical Parasitic Disedises. Practical Methods in Clinical Inmunology, Vol. 2, Chutchill Livingstone, London.

Garcia-Miss MR, Andrade- Varváez FJ, Esquivel-Viñas RF. Simmonds-Diaz EB, Canto-lara SB, Cruz-Ruiz AL 1990. Localized cutaneous leishmaniasis (chiclero's ulcer) in Mexico: sensitivity and specificity of ELISA for IgG antibodies to Leishmania mexicana mexicana. Trans $R$ Soc Trop Med Hyg 84: 356-358.

Guimaràes MCS, Celeste BJ, Franco EL 1990. Diagnostic performance indices for immunofleorescent test and enzyme immutioassays of leishmaniasis sera from northern and north-eastern Brazit. Bu/ WHO 68: $39-43$.

Hassan IfF, Coombs GiH 1987. Phosphomonoesterases of Leishmania mexicana mexicana and other flagellates. Mot Biochem Parasifol 23: 285-296.

Ilg T, Stierhof YD, Etges R, Adrian M, Harbecke D, Overath P 1991. Secreted acid phosphatase of Leishmania mexicana: a filamentous phospho-gly. coprotein polymer. Proc Nat Acad Sci USA 88: $8774-8778$.

Moody SF 1993. Molecular variation in Leishmania. Acta Tropica 53: 185-204.

Navin TR, Arana FE, Mérida AM, Arana BA, Castillo L. Silvers DN 1990. Cutaneous Leishmaniasis in Guatemala: Comparison of diagnostic methods. $A m$ JTop Med Hyg 42:36-42.

Seidelin H 1912. Leishmaniasis en Yucatan. Rev Med Yucatón (México) 26: 294-296.

Souza W'JS, Sabroza PC, Santos CS, Sousa E, Henrique MF, Coulinho SG 1992. Montenegro skin tests for Ametican cutancous leihsmaniasis carricd out on school children in Rio de Janciro, Brazil: an indicator of transmission risk. Acta Tropica 52:1] [-119.

Towbin H, Stachclin T, Gordon J 1979. Electrophoretic transfer of proteins from polyacrylamide gels to nitroceliulose shects: procedure and some applications. Proc Natl Acad Sci USA 76: 4350-4354.

Velasco O, Savarino SJ, Walton BC, Gam AA, Neva FA 1989. Los ágentes ctiológicos de la leishmaniasis cutánea en México. Rev Lat-amer Microbiol 31: $231 \cdot 234$. 